\title{
A Teoria da Complexidade de Edgar Morin e o Ensino de Ciência e Tecnologia
}

Virginia Ostroski Salles virginia.utfpr@gmail.com 0000-0002-3027-9845

Universidade Tecnológica Federal do Paraná - campus Ponta Grossa (Programa de Pós-Graduação em Ensino de Ciência e Tecnologia).

\section{Eloiza Aparecida Silva Ávila de}

\section{Matos}

elomatos@utfpr.edu.br

0000-0002-2857-4159

Paraná - campus Ponta Grossa

Paraná - campus Ponta Grossa
(Programa de Pós-Graduação em Ensino de Ciência e Tecnologia).

\section{RESUMO}

Este estudo apresenta um panorama da Teoria da Complexidade no contexto do ensino da ciência e tecnologia, visando contribuir nas reflexões teóricas acerca do tema. A opção metodológica é de caráter aplicado e descritivo, por promover justamente a discussão teórico-reflexiva em questão. Neste caminho, haverá uma discussão inicial que pretende situar a Teoria da Complexidade, pautada no pensamento de Edgar Morin, epistemólogo, expoente na estruturação deste campo de conhecimento há aproximadamente quatro décadas. Como continuidade da discussão proposta, será abordada a relação do ensino de ciência e tecnologia e sua complexidade. Fundamentalmente neste estudo, a busca da aproximação entre a perspectiva da complexidade e o campo da ciência e tecnologia serve para ampliar as questões que desafiam os rumos do conhecimento científico e tecnológico das décadas iniciais do século XXI, repletas de possibilidades e, ao mesmo tempo, com dilemas éticos e sociais que precisam ser superados para democratizar e socializar tais conhecimentos.
\end{abstract}

PALAVRAS-CHAVE: Complexidade. Ensino de Ciência e Tecnologia. Edgar Morin. 


\section{INTRODUÇÃO}

O presente estudo versa sobre as perspectivas do pensamento complexo no ensino de ciência e tecnologia, tendo como base teórica a Teoria da Complexidade, sob o ponto de vista de Edgar Morin. Uma constatação importante e necessária é colocar em evidência a figura deste epistemólogo francês que, ao longo de décadas, dedicou-se a construir as bases daquilo que caracteriza os apoios do pensamento ou da abordagem complexa. $\mathrm{O}$ artigo é uma revisão bibliográfica que busca aproximar a complexidade e as discussões acerca da ciência e tecnologia.

A longevidade de Edgar Morin, (completou 95 anos em julho de 2016) permitiu uma condição importante à vitalidade de seu pensamento complexo. $\mathrm{Na}$ medida em que acompanhou grande parte do século XX e tem acompanhado o início do século XXI, ele vem construindo reflexões fundamentais para nosso tempo. Ele fez parte da segunda grande guerra mundial nos anos 1940, da qual participou pelo exército francês, passando pelas décadas seguintes pela chamada "guerra fria" entre Estados Unidos e a ex-União Soviética, chegando ao século XXI com o terrorismo, a instabilidade atual no continente europeu e a perenidade da pobreza na África, bem como as desigualdades econômicas e sociais que afetam sobremaneira o desenvolvimento do continente americano. Assim, Edgar Morin pôde construir seu pensamento considerando a complexidade do mundo e da vida, os quais rejeitam respostas simples aos problemas multifatoriais do planeta.

Da mesma forma, não escaparam de Morin, as reflexões sobre o papel da ciência e da tecnologia ao longo de tantas décadas, que marcaram profundas mudanças no mundo, grande parte delas consideradas positivas, mas que, se analisadas com mais atenção, trouxeram com elas inúmeros problemas, igualmente profundos. A ciência, que trouxe novos medicamentos e a cura para inúmeras doenças, criou igualmente as armas e a morte. A ciência que criou a alta tecnologia, não se ocupou em refletir com a mesma vontade, sobre a desigualdade referente ao seu acesso, que ficou nas mãos das grandes corporações e de governos que, muitas vezes, utilizaram-na como instrumento de poder.

Portanto, como explicar o esgotamento dos recursos naturais no planeta, os riscos atuais pelas mudanças climáticas e os persistentes desastres ambientais causadores de mortes, além de mais pobreza e miséria, diante dos argumentos de que a ciência e a tecnologia mudaram o mundo? Diante deste contexto multifacetado e complexo, empreendemos este estudo.

\section{A COMPLEXIDADE QUE PERMEIA O ENSINO DE CIÊNCIA E TECNOLOGIA}

A partir do momento em que os sujeitos são entendidos como seres inacabados, e se constroem ao longo da vida, nota-se a importância do pensar a partir da complexidade humana, uma vez que são seres biológicos e culturais. Tal complexidade é, ao mesmo tempo, a possibilidade de ampliar seu pensamento sobre o mundo e a vida e, junto a isso, seu maior desafio à fragmentação do saberes humanos, científicos e da tecnologia. Diante disso, a Teoria da Complexidade ou pensamento complexo, que será tratado aqui, está intimamente ligada às questões desenvolvidas por Edgar Morin - pois é este estudo que se desdobra para romper com o pensamento simplificador e fragmentado que marca no âmbito escolar, entende-se como aquela que aceita sem questionar o 
isolamento dos conteúdos nas disciplinas, a memorização como possibilidade didática e a reprodução do conhecimento sem a reflexão profunda sobre seus problemas como: a desigualdade social, a pobreza, as dimensões éticas e morais, além da valorização da competição pelos melhores alunos expressa por notas.

Edgar Morin, que é um epistemólogo da contemporaneidade, tem contribuído de forma significativa nas áreas do conhecimento, tendo como princípio o pensamento que busca (re)ligar saberes que, por muito tempo, vem sendo tratado em lacunas, em fragmentos. De acordo com Morin (ALMEIDA; CARVALHO, 2002, p. 37), "a organização disciplinar institui-se no século XIX com a formação de universidades modernas, e desenvolveu-se no século XX com o progresso da pesquisa científica". Neste mesmo viés, Petraglia (2001), subsidiada pelas ideias de Morin, nos esclarece:

O currículo escolar é mínimo e fragmentado. Na maioria das vezes, peca tanto quantitativa como qualitativamente. Não oferece, através de suas disciplinas, a visão do todo, do curso e do conhecimento uno, nem favorece a comunicação e o diálogo entre os saberes; dito de outra forma, as disciplinas com seus programas e conteúdos não se integram ou complementam, dificultando a perspectiva de conjunto e de globalização, que favorece a aprendizagem. (2001, p. 69).

Assim, a fragmentação do saber apresenta lacunas que não oferecem uma abordagem de ligação entre áreas, limitando e, até mesmo, dificultando a aprendizagem dos envolvidos com o processo de ensino. Neste sentido, podemos afirmar que o essencial na abordagem da complexidade é o entendimento de que o todo necessita das partes, assim como as partes necessitam do todo para que ocorra uma efetivação de ambas. Isso não se trata de desvalorizar o avanço do pensamento disciplinar, mas não considerá-lo como a única via de desenvolvimento. O contrário também é verdadeiro, que não se pode constatar um pensamento amplo se não se considerar que ele é composto de vários elementos.

É necessário, portanto, encontrar formas de aproximar, conectar e interligar estes saberes, compondo um fluxo que caminhe entre, no meio e além das próprias áreas de conhecimento. Supondo o caminho da complexidade, pode-se confirmar esta hipótese no seguinte pensamento:

Ora, o problema da complexidade não é o de estar completo, mas sim do incompleto do conhecimento. Num sentido, o pensamento complexo tenta ter em linha de conta aquilo de que se desembaraçam, excluindo, os tipos mutiladores de pensamento a que chamo simplificadores e, portanto, ela luta não contra o incompleto, mas sim contra a mutilação. Assim, por exemplo, se tentarmos pensar o fato de que somos seres simultaneamente físicos, biológicos, sociais, culturais, psíquicos e espirituais, é evidente que a complexidade reside no fato de se tentar conceber a articulação, a identidade e a diferença entre todos estes aspectos, enquanto o pensamento simplificador ou separa estes diferentes aspectos ou os unifica através de uma redução mutiladora. Portanto, nesse sentido, é evidente que a ambição da complexidade é relatar articulações que são destruídas pelos cortes entre disciplinas, entre categorias cognitivas e entre tipos de conhecimento. De fato, a aspiração à complexidade tende para o conhecimento multidimensional. Não se trata de dar todas as informações sobre um 
sociocultural e que os fenômenos sociais são, simultaneamente, econômicos, culturais, psicológicos, etc. Dito isto, o pensamento complexo, não deixando de aspirar à multidimensionalidade, comporta no seu cerne um princípio de incompleto e de incerteza (MORIN, 1998, p.138).

O pensamento de Morin (1998) contribui no esclarecimento e na pertinência da perspectiva da complexidade ao permear e articular os saberes disciplinares, para que a partir daí, se possa efetivar a compreensão do todo. Ao mesmo tempo, a complexidade chama atenção para o respeito das diversas dimensões do ser, o que aponta a incompletude e a incerteza como pontos importantes para serem pensados, ao dimensionar tal pensamento.

Neste cenário, é fundamental entender que a complexidade, já apresenta em si mesma, uma dificuldade inicial, que é considerar o ser humano em várias dimensões, entre objetividade e subjetividade, entre questões sobre si mesmo, a vida e o mundo, entre ser (sentido humano) e ter (sentido material). Considerando estas observações, é importante já situar o ensino de ciência e tecnologia e como o seu desenrolar é permeado de complexidade. Segundo Bazzo (2014):

\begin{abstract}
A ciência e a tecnologia se baseiam em valores do cotidiano de cada época, que põem em questão as nossas convicções e o nosso conhecimento de mundo. Elas são, na maioria de seus aspectos, a aplicação sistemática de alguns valores humanos, tais como a diligência, a dúvida, a curiosidade, a abertura para novas ideias, a imaginação, e de outros como a disciplina e a perseverança, que precisam ser despertados em todos os seres humanos. Não são apenas os cientistas ou os tecnólogos que devem respeitá-las ou entendê-las. É preciso que todas as pessoas sejam conscientizadas do amplo universo que a ciência e a tecnologia incorporam e como os seus valores demonstram dramaticamente o seu grau de importância no avanço do conhecimento, do bem-estar e, também, de riscos e prejuízos. Por conseguinte, se a ciência e a tecnologia forem ensinadas e construídas nestas perspectivas junto a todos, o resultado será o reforço dos valores humanos indispensáveis para nossa compreensão de mundo. (BAZZO, 2014, p. 31-32)
\end{abstract}

Quando o autor fala dos valores da ciência e da tecnologia, não se encontram somente pistas, mas evidências sobre a sua complexidade. Isso remete a compreender a importância do entrelaçar deste trabalho, pois o conjunto das contribuições do pensamento complexo é justamente refletir sobre um pensamento global, planetário, uno; sem deixar de dar a devida importância aos elementos que compõem o todo.

Com estas pistas, observa-se que algumas questões já podem e devem prever novas perspectivas. Uma destas é justamente o argumento sobre o "desenvolvimento". Historicamente, se aponta para a ideia de desenvolvimento como vertente apenas econômica. Tal questão, ainda muito presente no pensamento mundial, ignora os seres humanos, a natureza e um futuro melhor para a humanidade. Neste contexto, como figuram as questões referentes ao ensino de ciência e tecnologia? Vejamos:

É inegável a contribuição que a ciência e a tecnologia trouxeram nos últimos anos. Porém, apesar desta constatação, não podemos confiar excessivamente nelas, tornando-nos cegos pelo conforto que nos proporcionam cotidianamente, seus aparatos e dispositivos técnicos. Isso pode resultar perigoso porque, nesta anestesia que o deslumbramento da modernidade tecnológica nos oferece, podemos nos esquecer de que a ciência e a tecnologia incorporam questões sociais, éticas e políticas. (BAZZO, 2014, p. 129) 
A tarefa de pensar a complexidade como uma possibilidade de religação de saberes, conhecimentos e formas de viver, está relacionada à importância de pensar simultaneamente o ensino de ciência e tecnologia. Pois, isto objetivará um desdobramento abrangente, não mais vendo a ciência e a tecnologia como uma forma de salvamento, conforto e evolução, mesmo que sejam viáveis apenas para uma parte dos habitantes do planeta, ignorando questões como guerras, migrações em massa, mortes pela miséria, desastres ambientais, além de toda a cultura do consumo, que esgota o planeta e a própria vida.

Pensando além, poderíamos supor que isso é inversamente proporcional ao que vislumbramos sobre uma cidadania planetária, voltada à vida, esperança, solidariedade e sustentabilidade. Essas preocupações, que emergem nas discussões da contemporaneidade, são questões que podem fazer parte dos currículos de ensino, para que façamos de fato uma educação com consciência, almejando contribuir para a formação mais completa das pessoas, e não apenas de uma ciência que reproduza o conhecimento, mas formas de viver a vida e conceber o planeta.

Nesse sentido, o pensamento de Edgar Morin figura entre as boas alternativas reflexivas para o cotidiano da vida atual, entre saberes e fazeres, entre entender a ciência e a tecnologia como possibilidades de desenvolvimento humano, com sustentabilidade e não mais fragmentos que não se encontram. Ciência e tecnologia, quando são colocadas à prova de sua possibilidade de humanização e melhoria da vida das pessoas, precisam ter respostas mais amplas, consistentes e, especialmente, analisadas sobre os fatos concretos. Atualmente, negar os avanços na ciência e tecnologia é ingenuidade. Porém, ingenuidade maior é fechar os olhos à desigualdade e aos problemas gerados por elas, desde o não acesso pelas camadas pobres, até as questões relacionais e psicológicas cada vez mais em evidência pelo isolamento das pessoas no chamado "mundo virtual".

\section{Alguns Apontamentos sobre o Ensino de Ciência e Tecnologia}

O ensino de ciência e tecnologia, em alguns momentos, é alvo de discursos de senso comum, o que nos faz acreditar que é necessário fortalecer as discussões acerca da temática, para intensificar seu importante papel na educação das próximas gerações. Vemos que a UNESCO (2005 p. 2) é incisiva em seu entendimento sobre o risco da educação científica insuficiente: desenvolvimento da economia e da indústria, a educação científica e tecnológica é, também, essencialmente importante no processo de promoção da cidadania e inclusão social, uma vez que propicia às pessoas oportunidades para discutir, questionar, compreender o mundo que as cerca, respeitar os pontos de vista alheios, resolver problemas, criar soluções e melhorar sua qualidade de vida. Além disso, a aprendizagem dos alunos na área científica é reconhecidamente importante, uma vez que está relacionada à qualidade de todas as aprendizagens, contribuindo para desenvolver competências e habilidades que favorecem a construção do conhecimento em outras áreas. Portanto, quando se melhora a educação científica não se melhora só a aprendizagem de Ciências: o seu impacto atinge outros campos. 
Percebemos que, nesta perspectiva, o trabalho das políticas de educação científica e tecnológica deve estar relacionado à totalidade da vida e das aprendizagens, ou seja, procurando visar um desenvolvimento educacional completo. Com isso, poderíamos supor que esta situação é capaz de auxiliar no processo de formação de cidadania, desenvolvendo a totalidade do ser. Considerando estes pontos, é importante que sejam feitas investigações claras e que permeiem o campo educacional, trazendo oportunidade de discussão sobre a ciência e a tecnologia e seus avanços positivos, além de seus apontamentos críticos e possíveis mudanças.

Tais mudanças não estão, necessariamente, na forma de operacionalizar a ciência, com seus métodos eficazes e seus protocolos meticulosos. Está, especialmente, em dotá-la de "humanização", de destinar o mesmo espaço e valor do papel da necessidade de torná-la acessível à maior parte dos seres humanos. Como aceitar com normalidade o fato do homem conseguir comunicar-se em tempo real com lugares tão distantes do planeta e, até mesmo, fora dele, quando ao mesmo tempo, milhões de crianças morrem de diarreia e/ou por falta de alimentação básica em outros locais do mesmo planeta? Igualmente, como aceitar que uma pequena parcela da população tenha carros e casas "inteligentes", onde tudo funciona pela voz, do acender ao apagar das luzes, enquanto dezenas de milhões de seres humanos migram por várias regiões do globo, sem ter onde dormir, fugindo das guerras geradas inclusive pelo domínio da tecnologia?

Como esclarecimento destas questões, devemos fortalecer o pensamento crítico de forma que não seja mais possível aceitar passivamente a questão da neutralidade da ciência e da tecnologia, em relação a quem tem mais acesso e/ou trabalha com ela. Precisamos, com urgência, ampliar o entendimento de que não há somente melhoramentos para nossas vidas, mas também, nos coloca à mercê de tantos riscos e perigos.

\footnotetext{
Há muitos anos, a ciência e a tecnologia vêm ditando os rumos e alternâncias do comportamento social, tanto no plano industrial quanto nos setores individuais das pessoas. Esta mudança, decorrente de satisfazer as necessidades cotidianas nas questões de sobrevivência, desenvolvimento, lazer, geração de supérfluos, vem entupindo a sociedade de aparatos tecnológicos que, na maioria das vezes, os usuários nem sequer imaginam como operar. (BAZZO, 2014, p. 118)
}

Quando se declaram estas evidências, estamos pensando criticamente diante desses argumentos, o que é importante, pois aprendemos, até hoje, a separar, fragmentar conhecimentos, ficando claro que é preciso reaprender a ligar/religar saberes. Mas, não paramos por aqui, ainda é necessário, percebermos também, a evolução e os avanços em pesquisas que a ciência e a tecnologia vêm realizando.

Constata-se que a área das ciências, de maneira geral, tem se aproximado mais "naturalmente" das questões até aqui desenvolvidas. Acreditamos que não são essas questões que mais precisam dessa revisão, da metamorfose na abordagem, de unir segmentos(???) de ponta da ciência e da tecnologia, com igual pensamento vigoroso sobre seus impactos na vida das pessoas, não só os possíveis impactos positivos, mas também, os problemas decorrentes de seu campo. Podemos observar um início desta mudança abaixo: 
fenômenos complexos que envolvem, por exemplo, a dinâmica dos fluídos, desde o escoamento em tubos, até a circulação sanguínea. São novos modelos que possibilitam novos alcances para aprendizagem em qualquer nível de escolaridade. (ANGOTTI, 2001, p. 7)

Tal pensamento nos mostra que a tecnologia proporciona rumos muito importantes para a ciência, mas que, ao mesmo tempo, devem estar a serviço da melhoria da vida e do planeta, e não do esgotamento dos recursos naturais e nas mortes prematuras de pessoas que não têm acesso aos avanços científicos e tecnológicos. Aqui, cabe uma observação recorrente de Morin (2005), que diz que a ciência se torna cega ao desconsiderar os problemas que ela mesma cria.

Assim, o que podemos e devemos articular até aqui, é a necessidade, importância e urgência deste repensar ciência e tecnologia, de reunir com mais disposição os diferentes saberes, as áreas do conhecimento, para pensar em desenvolvimento com sustentabilidade, que supõe valorizar igualmente as máquinas, as pessoas e o meio ambiente. As ciências naturais, humanas e sociais precisam perceber-se no mesmo movimento a favor do mundo e da vida. O processo transdisciplinar, aquele que vai ao lado e entre as diferentes áreas, precisa ser incentivado. Não é possível mais, diante do esgotamento do discurso que a ciência só traz benefícios, insistir na divisão e competição entre as áreas, uma vez que, se analisarmos criticamente, todos estão perdendo, em vida, em saúde, em crenças.

\title{
Aproximando Saberes: complexidade e ensino de ciência e tecnologia
}

Como expõe Morin (2005, p. 18), "a inteligência cega destrói os conjuntos e a totalidade isola todos os objetos daquilo que os envolve. Não pode conceber o elo inseparável entre o observador e a coisa observada". Coloquemos em prática a 'complementaridade' para superarmos a incapacidade de articular os saberes em que estamos imersos. A complexidade de que tratamos aqui vem do apontamento de Morin (2003, p. 38) que diz:

\begin{abstract}
Complexus significa o que foi tecido junto; de fato, há complexidade quando elementos diferentes são inseparáveis constitutivos do todo (econômico, o político, o sociológico, o psicológico, o afetivo, o mitológico), e há um tecido interdependente, interativo e inter-retroativo entre o objeto de conhecimento e seu contexto, as partes e o todo, o todo e as partes, as partes entre si. Por isso, a complexidade é a união entre a unidade e a multiplicidade.
\end{abstract}

A complexidade nos faz reconhecer o que, realmente, ainda precisamos avançar na integração dos saberes, das áreas de conhecimento e entre o verdadeiro papel a ser redimensionado em relação à ciência e tecnologia, nessa unificação com a sociedade. Conforme explicita Morin, ao falar do complexus, temos a economia que é importante, mas não é a única possível de abordar a ciência e tecnologia. Temos o fator político, não só na regulação e criação de critérios para o desenvolvimento da ciência e tecnologia, mas exatamente na forma de relacioná-los às políticas de desenvolvimento das pessoas e do planeta.

Na continuidade deste complexus temos um cenário sociológico, que nos ajuda sobremaneira a perceber os cenários, as desigualdades e possibilidades de utilizar a ciência e tecnologia como desenvolvimento da vida e preservação da 
natureza. Igualmente as questões psicológicas, afetivas e mitológicas, que entendem o ser humano em sua subjetividade, que não é exato como as máquinas, mas tem toda uma expectativa além da ciência e tecnologia, que é sua vida nos amores, dores, relacionamentos, crenças, espiritualidade e transcendência. Parece-nos que um dos maiores desvios no desenvolvimento da ciência e da tecnologia nas últimas décadas, foi, paradoxalmente, reduzir o ser humano ao cognitivo, apenas ao intelecto, suprimindo suas sensações e sentimentos, em nome da "neutralidade" e "imparcialidade" do conhecimento, que como atividade humana, social e histórica, nunca serão neutros e imparciais.

É importante reconhecer que muito já tem sido feito neste sentido. Uma destas iniciativas, em escala mundial, foi estabelecida pela Organização das Nações Unidas (ONU) dentro do documento intitulado "Agenda 2015-2030" para o desenvolvimento sustentável, onde são previstos 17 objetivos e 169 metas para provocar mudanças sensíveis no planeta e na vida das pessoas. Estes objetivos do desenvolvimento sustentável tratam de áreas que vão desde a redução da pobreza, passando pela justiça, moradia, saúde, educação e direitos humanos, até questões sobre a criação de novas fontes de energia, cuidado com a biodiversidade, com os mares e com toda a natureza. Acreditamos que caminhos como estes estarão mais evidenciados nestes próximos anos, visando humanizar a ciência e a tecnologia.

\section{CONSIDERAÇÕES FINAIS}

A discussão aqui encaminhada procurou alertar para alguns pontos importantes. O primeiro foi dotar a ciência e a tecnologia com uma humanização necessária e que deve ser crescente ao tratar dos temas. A clareza perante os fatos mais comuns e cotidianos de que ignorar o ser humano, com sua subjetividade, nas situações de pobreza e miséria, em que a ciência e a tecnologia (em sua vontade de criar, avançar e contribuir com o desenvolvimento da humanidade) perderam a própria perspectiva e entendimento sobre o termo desenvolvimento. Conservar os parênteses.

Assim, podemos dizer que a ciência evoluiu e o cérebro ficou mais forte e treinado. Nesse contexto, o corpo foi esquecido, o corpo que vive, que paga as contas, que sente amor, medo, insegurança perante a morte, e até perante a vida. Ou seja, a ciência e tecnologia trouxeram desenvolvimento, para o bem e para o mal.

Neste cenário, a Teoria da Complexidade de Edgar Morin nos inspira a mapear, entender e reconstruir passos nesse encontro entre ciência, tecnologia, sociedade, ser humano e planeta. Não se pretende rivalizar ou instigar competição entre estas áreas, mas fazer esforços para integrá-las, para que caminhem próximas, entrelaçadas, questionando seu papel nas próximas décadas. Levar as referidas áreas a descobrir o caminho para que o tão enfatizado "desenvolvimento" possa realmente assimilar a noção de sustentabilidade da vida em toda sua plenitude, dentro da visão dos direitos humanos fundamentais e na busca de transcendência e realização plena do ser humano. 
Morin (2013) enfatiza que estamos chegando à beira do abismo deste modelo de sociedade. Neste abismo só há duas possibilidades: cair ou mudar. Enfim, realizar a metamorfose, dar pequenos passos, mas com determinação, rumo a novos entendimentos. Isso só poderá ser feito a partir do pensamento complexo. 


\title{
THEORY COMPLEXITY IN MORIN EDGAR AND SCIENCE EDUCATION AND TECHNOLOGY
}

\begin{abstract}
This study presents an overview of complexity theory in the context of the teaching of science and technology to contribute in theoretical reflections on the subject. The methodological approach is applied and descriptive, for just promote theoretical and reflective discussion in question. In this way, there will be an initial discussion that you want to place the Complexity Theory, based on the thought of Edgar Morin, Epistemologist exponent in the structuring of this field of knowledge for nearly four decades. Continuity of the proposed discussion, the relationship of teaching science and technology and the complexity will be addressed. Fundamentally this study, the pursuit of closer ties between the perspective of complexity and the field of science and technology serves to broaden the issues facing the direction of scientific and technological knowledge of the early decades of this century, full of possibility and at the same time, with ethical and social dilemmas that need to be overcome to democratize and socialize such knowledge.
\end{abstract}

KEYWORDS: Complexity. Science Education and Technology. Edgar Morin. 


\section{REFERÊNCIAS}

ALMEIDA, C. de; CARVALHO, E.A. (org.). Edgar Morin. Educação e complexidade: os sete saberes e outros ensaios. Trad. Edgar de Assis Carvalho. São Paulo: Cortez, 2002.

ANGOTTI, J. A. P. Ensino de Ciência e Complexidade. In: VI Escola de Verão de Investigação-ação em Ensino de Física, 2001, Ponta Grossa, PR. Anais da VI Escola de Verão de Investigação-ação em Ensino de Física. Ponta Grossa, PR: UEPG, 2001. v. 01. p. 29-43.

BAZZO, W. A. Ciência, Tecnologia e Sociedade: e o contexto da educação tecnológica. 4a ed. Florianópolis: Editora da UFSC, 2014.

ORGANIZAÇÃO DAS NAÇÕES UNIDAS (ONU). Transformando nosso Mundo: a agenda 2030 para o desenvolvimento sustentável. Traduzido pelo Centro de Informação das Nações Unidas para o Brasil (UNIC Rio), última edição em 08 de setembro de 2015 .

MORIN, E. A Via para o futuro da humanidade. Rio de Janeiro: Bertrand Brasil, 2013.

Ciência com Consciência. 2a ed. Rio de Janeiro: Berhand, 1998

Introdução ao pensamento complexo. Porto Alegre: Sulina, 2005.

Notas para um "Emílio" Contemporâneo. In: PENA-VEJA, A.; ALMEIDA, C. R. S.; PETRAGLIA, I. (orgs). Edgar Morin: Ética, Cultura e Educação. Ed. Cortez, São Paulo: 2003.

PETRAGLIA, I. C. A Educação e a Complexidade do Ser e do Saber. 5á ed. Petrópolis: Vozes, 2001. 
UNESCO. ENSINO DE CIÊNCIAS: O Futuro em Risco. 2005. Disponível em: <http://unesdoc.unesco.org/images/0013/001399/139948por.pdf> Acesso em: 26 jul. 2016.

DOI: $10.3895 /$ rbect.v10n1.5687

Como citar: SALLES, V. O.; MATOS, E. A. S. Á. A Teoria da Complexidade de Edgar Morin e o Ensino de

Ciência e Tecnologia. Revista Brasileira de Ensino de Ciência e Tecnologia, v. 10, n. 1, 2017. Disponível em: <https://revistas.utfpr.edu.br/rbect/article/view/5687>. Acesso em: xxx.

Direito autoral: Este artigo está licenciado sob os termos da Licença Creative Commons-Atribuição 4.0

Internacional. 